\title{
Buzz at workplaces in knowledge-intensive service production: Spatial settings of temporary spatial proximity
}

European Urban and Regional Studies 2019, Vol. 26(4) 434-448 (C) The Author(s) 2018

Article reuse guidelines: sagepub.com/journals-permissions DOI: I0.1 I77/09697764/8784999 journals.sagepub.com/home/eur (S)AGE

\author{
Anna Growe \\ Heidelberg University, Germany
}

\begin{abstract}
The objective of this paper is to understand temporary spatial proximity beyond temporary clusters, and to analyse rationales for the use of various spatial settings for temporary spatial proximity in the work processes of knowledgeintensive services. To contrast different types of temporary spatial proximity two basic types, 'Meet and Mingle' and 'Move and Manage', are identified. On the basis of qualitative interviews in knowledge-intensive sectors in six German cities, the distinct use of three types of spatial settings (workplaces, transit places and retreat places) to create the targeted temporary spatial proximity type of 'Move and Manage' is analysed. The paper discusses how such settings contribute to creating a specific atmosphere to support the work processes of knowledge-intensive services.
\end{abstract}

\section{Keywords}

Buzz, face-to-face, knowledge-intensive services, spatial proximity, temporary cluster, temporary proximity, workplace

\section{Physical places of temporary spatial proximity}

The importance of face-to-face contact for the transaction of economic processes, particularly for the exchange of knowledge and information, has long been a topic of discussion, in many contexts, in the field of geography (Asheim et al., 2007; Storper and Venables, 2004). The positive effects of face-to-face communication arise from co-location. Observation and intensive interaction, through immediate spatial proximity, facilitate the exchange and creation of tacit knowledge, trust and conflict resolution (Gertler, 2003; Nilsson and Mattes, 2015; Rutten, 2017).

Since the mid-2000s, however, it has been highlighted that co-location must, by no means, be permanent to have these positive effects (Gertler, 2008; Maskell et al., 2006). Temporary spatial proximity can also facilitate face-to-face interaction and utilise the positive effects of this type of communication (Henn and Bathelt, 2015; Jansson, 2014; Li, 2014; Robertsson and Marjavaara, 2014; Torre, 2015). The traditional focus on analysing stakeholder constellations in temporary spatial proximity

\footnotetext{
Corresponding author:

Anna Growe, Department of Geography, Heidelberg University, Berliner Straße 48, 69I20 Heidelberg, Germany.

Email: anna.growe@uni-heidelberg.de
} 
has concerned processes of social interaction. Processes of interaction in co-location not only enable knowledge transfer through observation and interaction, but also create a specific dynamic and innovative atmosphere. The interrelation of interaction and creating a specific atmosphere in temporary spatial proximity can be understood as 'buzz' (Bathelt and Schuldt, 2010; Maskell et al., 2006). Bathelt et al. (2004: 38) summarised that 'buzz refers to the information and communication ecology created by face-to-face contacts, co-presence and colocation of people and companies within the same industry and place or region'.

Although physical places are explicitly mentioned as part of the definition, so far social interaction has been the main focus of studies dealing with buzz (Currid and Williams, 2010; Mould and Joel, 2010). Regarding temporary spatial proximity, the concept of buzz is mainly associated with interaction during temporary clusters; however, other types of temporary spatial proximity have not been analysed in conjunction with the concept of buzz.

Buzz has also been referred to as a 'general excitement' (Mould and Joel, 2010: 283) supporting the creation of new ideas. The core argument of this paper is, however, that processes of interaction are only one part of the equation. There are two tools supporting the creation of a specific dynamic and innovative atmosphere: interaction processes and the physical places where interaction takes place (Allen and Henn, 2007). Physical places influence the way people discuss or feel, as well as what can be observed and realised.

The influence of the physical environment on organisation and work output has been discussed primarily in architecture (e.g. Borges et al., 2013; Georgi, 2016; Kohlert and Cooper, 2017) and management research (e.g. Allen and Henn, 2007; Brown and Kātz, 2009; Miller, 2014). In economic geography, the interrelation of physical places and interaction processes has just recently been brought into focus (e.g. Flögel and Zademach, 2017). The focus here has been the use of specific company intern places to influence service-client interaction in financial services.

This paper, however, combines a discussion of the different types of physical places that support temporary spatial proximity with the question of how these places contribute to creating a supporting buzz. Questions discussed in this paper are as follows: what types of spatial settings are used for creating temporary spatial proximity in the work processes of knowledge-intensive services and how do the identified spatial settings contribute to creating a specific atmosphere supporting the work processes?

To answer these questions, the first part of the paper examines two basic types of temporary spatial proximity through an examination of knowledgeintensive sectors in six German cities: 'Meet and Mingle' and 'Move and Manage'. The second part introduces a framework of three spatial settings for the 'Move and Manage' type. The three spatial settings are used as an analytical framework to understand the benefits they provide to work processes. The third part introduces the qualitative approach of the study, the knowledge-intensive service sectors where interviews were conducted, the number and background of interviewees that are met in German cities and an analysis of the interview material. The fourth section provides the empirical results of the interviews, and interprets them in the context of the analytical framework presented in the second part. The fifth part summarises the answers to the questions concerning the settings of temporary spatial proximity in the work processes of knowledgeintensive services, derived from the qualitative interviews, as well as the reasons for the spatial settings.

\section{Forms of temporary spatial proximity}

The term 'temporary spatial proximity' has been used to discuss temporary measures to establish and maintain interaction between partners not always leading to long-term or permanent constellations, such as the establishment of a branch office (Maskell et al., 2006; Rychen and Zimmermann, 2008; Torre, 2008). Papers on temporary spatial proximity have a primarily microanalytic perspective, focusing on specific types of temporary clusters (Bathelt and Henn, 2014; Bathelt and Schuldt, 2008; Henn and Bathelt, 2015) or the role that temporary spatial proximity plays in learning processes (Bathelt and Gibson, 2015; Grabher, 2004; Grabher and Thiel, 2015; Müller and Stewart, 2015). 
Rychen and Zimmermann (2008: 772) introduced two types of temporary spatial proximity: (a) temporary clusters; and (b) 'moving'. They conceptualised temporary clusters as specific settings that sought and found new partners, whereas 'moving' refers to bilateral or multilateral relations between companies that are already partners. This distinction helps to identify two types of temporary spatial proximity occurring during work processes; however, an analysis of different physical places, enabling temporary face-to-face interaction through providing physical proximity, is missing.

\section{Meet and Mingle}

A huge body of literature can be identified that analyses the spatial settings and interaction processes during temporary clusters. Clusters are described as 'a geographically proximate group of inter-connected companies and associated institutions in a particular field, linked by commonalities and complementarities' (Porter, 2003: 254). Opportunities for the exchange of sticky, non-articulated knowledge are provided in clusters. Although clusters have long been treated as permanent, for example, located in built structures of a specific building, in parts of a city or within a region, Maskell et al. (2006) emphasised that they are not permanent by definition. Clusters exist only for as long as the actors in the cluster interact with each other. The particular advantage of temporary clusters - in comparison to permanent spatial clusters - is that knowledge stemming from the local sources of each actor can be combined in innovative ways, with tacit forms of external knowledge sources (Bathelt et al., 2004; Li, 2014). Participating in temporary clusters is understood to be a temporary measure, enabling access to knowledge sources from distant spaces.

In most studies, temporary clusters are consistently typified by the examples of trade fairs (Bathelt and Gibson, 2015; Ramírez-Pasillas, 2008; Rinallo and Golfetto, 2006), conferences and exhibitions (Cook and Ward, 2012; Entwistle and Rocamora, 2006; Henn and Bathelt, 2015; Norcliffe and Rendace, 2003) and award ceremonies (Anand and Watson, 2004). These meetings are gatherings of a community connected through work (Bathelt and Henn, 2014) and facilitate work in global networks through enabling dense interaction with numerous actors that are usually located in different geographical places. Reciprocal communication patterns between actors of an industry result in a vibrant atmosphere where inspiration and information can be received through interaction and observation, helping to reduce information asymmetries and uncertainties in extra-local interaction. The rich information flows generated during temporary clusters are called 'global buzz'. Temporary clusters, therefore, serve as pipelines to access the global buzz by dispatching mobile professionals to learn in global knowledge networks (Maskell et al., 2006; Bathelt and Schuldt, 2008, 2010; Schuldt and Bathelt, 2011).

Recently, connecting the concept of the field-configuring event with temporary spatial proximity has gained prominence in economic geography studies (Lange et al., 2014). With this concept, market structuring mechanisms (Lampel and Meyer, 2008) and questions of power are focused. Field-configuring events conceptualise temporary spatial proximity as power arenas where power relations are displayed spatially (Levy and Scully, 2007; Schüßler et al., 2015). In this context, intangible assets, such as reputation or symbolic capital, are important (Anand and Watson, 2004; Lange et al., 2014) and the relations of the spatial embeddedness of social interaction are emphasised (Power and Jansson, 2008).

With temporary clusters, stakeholders meet for a certain, predetermined period of time, at a specific location, usually away from the places in which the participants live and work. Temporary clusters also involve a greater number of stakeholders who may not necessarily know each other in advance. These clusters provide opportunities to exchange information with a previously undefined number of stakeholders, combined with opportunities to meet new stakeholders (Bathelt and Schuldt, 2010). Communication is thus characterised by openness and the unknown (Bathelt and Gibson, 2015; Bathelt and Henn, 2014). By participating in temporary clusters, new contacts can be established, old contacts reinforced, competitors observed and the need to be part of a community satisfied (Rallet and Torre, 2009). Temporary clusters as informal community gatherings can also be linked with other events, for example, societal, cultural or sport events that are sponsored by actors of the 


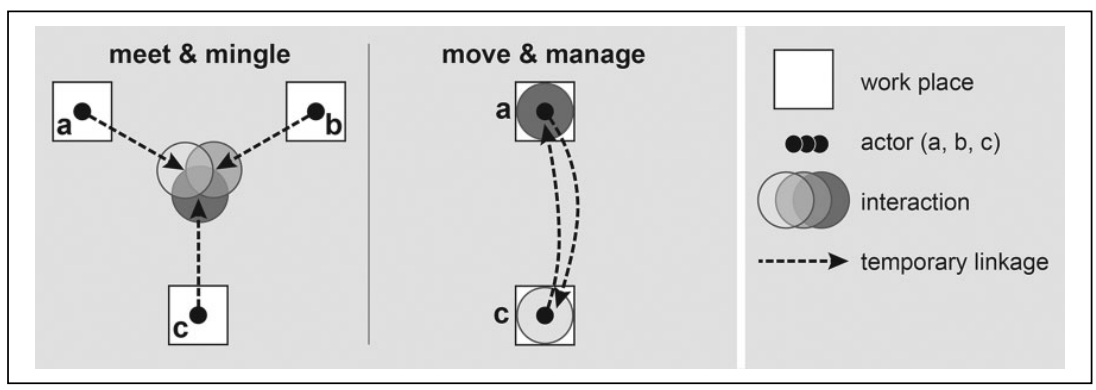

Figure I. Two main types of temporary spatial proximity. Source: Own diagram, based on Rychen and Zimmermann (2008).

respective community or have other linkages to important actors within the community.

Being liberated from their daily work routines, participants in temporary clusters become more open and accessible, and it is easier for them to contact each other. By offering the possibility to interact face-to-face, temporary clusters facilitate the conclusion of business transactions and the deepening of interactions with existing partners (Bathelt and Schuldt, 2008). Meeting and mingling to participate in a vibrant atmosphere with existing, as well as potentially new, partners is one crucial differentiator between temporary clusters (hereafter referred to as the 'Meet and Mingle' type) and targeted meetings (see Figure 1).

\section{Move and Manage}

In contrast to 'Meet and Mingle', the 'Move and Manage' type of temporary spatial proximity (see Figure 1) is geared towards a particular place and stakeholder. The focus herein is on bilateral and multilateral exchanges with predetermined stakeholders, targeting predetermined objectives.

'Move and Manage' occurs as a basic type of temporary spatial proximity in almost all business processes. Face-to-face communication with remotely located partners can occur in the everyday working context, for example, in meetings between the provider and consumers of services that occur during the process of service production in the offices of the service provider and, therefore, in a setting that has not specifically been built for such an encounter (Grabher, 2002a, 2002b, 2004; Ibert, 2004).
Usually, temporary spatial proximity of the 'Move and Manage' type is integrated into phases of longdistance cooperation, in which interaction via information and communication technologies takes place (Torre, 2011). Regarding social interaction, Bathelt and Henn (2014) differentiated three circumstances under which travel is necessary to create face-toface-encounters: intra-company business coordination; producer-user meetings; and inter-company business negotiations. These meetings can be relatively short with predetermined stakeholders and a prepared agenda, and are usually framed through virtual communication (Rallet and Torre, 2009). While virtual communication is seen as an opportunity to avoid regional economic lock-in effects in one strand researching virtual forms of co-presence, the inefficiency of these forms of communications still has to be accompanied through face-to-face interactions, emphasising the temporary mobility of individuals (Bathelt and Turi, 2011). In other studies a differentiation between places of a person's location and the cognitive focus is introduced, illustrated by contrasting the terms 'being there' and 'being aware' (Grabher et al., 2017).

Relative to the physical dimension of interaction, Urry (2007) argued that, although travelling can be substituted by communication technologies, to a different extent in some cases, the reason for travelling might be to experience a specific place or to spend time together. The shortcomings of bodily experiences through virtual communication (as a lack of observation possibilities but also as a lack of effort put into the relationship; Strengers, 2015) increase the need for temporary mobility of individuals and enable 
a dense combination of 'being there' and 'being aware' (Grabher et al., 2017). Particularly when 'being aware' is not only used with regard to (isolated) social interactions but also with regard to the physical environment of social interactions, a relocation of individuals has to antecede observations. Hence, communication technologies cannot substitute for travelling and the benefits of physical encounters (Aguiléra et al., 2014; Faulconbridge et al., 2009). The meaning of physical encounters with specific persons at specific places is especially high if moving is understood as a serious commitment in the business relationship (Gustafson, 2013; Strengers, 2015). As moving bodies requires financial, temporal and physical efforts, and also causes inconvenience for the traveller, the investment made for a specific person or to visit a specific place demonstrates respect and is an investment in trust (Growe 2018).

Particularly at the start of a project, face-to-face interaction is important. Rallet and Torre (2009) argued that temporary work constellations in spatial proximity facilitate getting to know and trust contacts, developing a common concept and agreeing on the steps required to realise the concept, as well as reaching an agreement on the distribution of the expected costs and benefits. Thus, if people in the project do not become acquainted at the beginning of collaboration, if concepts are not developed or aligned, if the distribution of costs and benefits is not agreed upon, a successful joint effort during the project will be hard to reach or, in some cases, the project might fail before it really starts. The need for face-to-face interaction, therefore, can vary during a project's course.

The targeted 'Move and Manage' type of temporary spatial proximity brings not only physical mobility in an increasingly digital work environment into focus (Beaverstock and Budd, 2013; Gustafson, 2013), but also specific settings where meetings take place and people conduct work (Gallie and Guichard, 2005; McNeill, 2009). The interrelation of physical places and interactions is also confirmed by Rutten (2017). He argued that communication is influenced by specific places. Changing workplaces during projects can influence communication between individuals and the social dynamics in the work process (Rutten, 2014; Rutten and Boekema, 2012), and analysing specifically chosen physical places can reveal insights into processes and interactions taking place in these places (e.g. what places are chosen to support what kind of interaction?).

\section{Spatial settings of 'Move and Manage'}

Linked to the targeted nature of temporary spatial proximity of the 'Move and Manage' type, important questions relate to the reasons for choosing specific spatial settings, the expected benefits linked to specifically chosen spatial settings and to the embedding of diverse locations of temporary spatial proximity in different phases of the work process. These issues are of particular importance because this face-to-face communication does not always occur in places that are explicitly provided for large meetings, but also in - as Rallet and Torre (2009) put it - 'ordinary places'. Rallet and Torre (2009) contrasted 'ordinary places' with conference venues and other settings that enabled the formation of temporary clusters. Among 'ordinary places', Rallet and Torre (2009) included the following: (a) the workplaces of the stakeholders; (b) transit spaces, such as airports and train stations; and (c) bars and restaurants.

The specific characteristic of these settings is the possibility to meet with a group of people spontaneously, and still provide a certain form of closed work environment, be it a meeting room in an airport or train station, or a table in a restaurant. Although this is a shared characteristic of the three 'ordinary places', these places can also described with different terms, highlighting their distinctiveness.

In numerous studies, bars and restaurants have been associated with the term 'third places'-neutral public places that are neither home nor work (Jon Hawkins and Ryan, 2013; Oldenburg, 1999; Slater and Jung Koo, 2010). Usually, people gather voluntarily and informally in these places, to enjoy a comfortable, regenerative atmosphere. Spaces grouped under the term 'retreat places' provide dining and drinking facilities; however, the focus of these places is to retreat into a specific type of relaxed atmosphere.

Transit spaces have often been described using the term 'non-places' (Augé, 2008). These places are also neutral spaces; not usually being travel destinations, 
per se, they are used on one's way to somewhere else. The easy accessibility of these places allows a combination of travelling and meeting, and their anonymity can provide further advantages. Airports are particularly understood as 'non-places' in global processes (Costas, 2013; Pütz, 2012). An example of an analysis for integrating transit spaces in work processes is discussing airports as business locations (Gallie and Guichard, 2005; McNeill, 2009). The focus there, however, is mainly on only one very specific type of spatial setting. A study that considers the use of different spatial settings as workplaces through the perspective of a knowledge-based work process is, however, still pending.

Against this background knowledge, intensive services have been chosen as an empirical setting. Characterised by an intensive interaction between the providers and consumers of the service, knowledge-intensive services are a particularly interesting case (Bettencourt et al., 2002; Strambach, 2008). The commodity produced (the service) is typically intangible knowledge that is created by means of consulting activities in the form of solutions, whereby the expertise of the knowledge-intensive service provider is tailored to the needs of consumers. This might involve knowledge newly created for customers, or knowledge that customers could not make use of without the service provider's help (Wood, 2002). As service providers are not always located in dense spatial proximity to their clients, they rely heavily on strategies to interact virtually. The improvement of communication technologies has facilitated long-distance collaboration (Ibert, 2004); however, exchanging tacit knowledge and creating new knowledge are based on face-to-faceencounters (Gertler, 2003; Rutten, 2017), realised through producer-user meetings, a typical form of temporary spatial proximity of the 'Move and Manage' type. Knowledge-intensive services, as one particular case, can provide meaningful insights into the role physical places play during producer-user meetings (Bettencourt et al., 2002). What benefits do the chosen physical places provide to work processes that could not be provided in other locales? How do the two tools to create a specific dynamic and innovative atmosphere - interaction processes and physical places - interrelate in the chosen areas?
Table I. Stakeholders interviewed.

Interviews Advertising Consultancy IT consultancy Sum in

\begin{tabular}{lrrrr}
\hline Companies & 9 & 10 & 8 & 27 \\
Key players & 4 & 4 & 4 & 12 \\
Sum & 13 & 14 & 12 & 39 \\
\hline
\end{tabular}

Source: Own research.

IT: information technology.

Based on the differentiation of Rallet and Torre (2009), the following three spatial settings serve as a framework for analysing the interrelation of specific physical places with interaction processes during work practices: company workplaces; transit spaces; and retreat places.

\section{Data and methodology}

This study involved semi-structured, qualitative interviews with 39 stakeholders (see Table 1) in knowledge-intensive services. This implies a qualitative research design based on case studies in six German cities (the selected companies represented by the interviewees) to examine practices during the work process from the perspective of the actors, and the reconstruction of their motivations.

The interviews were conducted in three knowledge-intensive service industries in which there were different working priorities. Interviews were conducted with stakeholders in a management consultancy (with a focus on consulting as a product), stakeholders from advertising agencies (where the product is creative) and stakeholders from information technology (IT) consultancies (with a technical product).

Twelve of the interviewed stakeholders were identified as key representatives of trade associations and chambers representing the selected sectors in Germany. They provided overviews of the typical work processes and the demands of the respective services, including knowledge about work processes beyond the experience in one company. Furthermore, they provided access to stakeholders in service companies that would be willing to participate in the interviews. The 27 stakeholders interviewed at companies from the selected sectors were identified by a 
snowball sampling system, using the contact information provided by the key representatives. This sampling technique is often used to identify actors that are difficult for researchers to access. The sampling technique resulted in a spatial distribution of the interview partners focusing on six German cities, representing economically strong metropolitan regions in the polycentric urban system in the western part of Germany.

Twenty-two of the 27 interviewees in the companies were management-level senior executives. Five were engaged as consultants or advertisers. Apart from four, all of the interviews took place in the company or association of the interviewees, either in the interviewee's office or in a meeting room. Four interviews were completed in neutral places - one in a restaurant and three in coffee shops. In light of the confidential nature of the interviews, the interviewees and their companies or associations shall remain anonymous in the following discussion.

The interviews were conducted in German, the native tongue of the interviewees and interviewer, and translated into English for this paper. Each of the conducted interviews took between 1 and 2 hours. All interviews were recorded and transcribed. The transcripts were analysed through a process of coding and categorisation of meanings. The interviews followed an open interview guideline with narrative elements, enabling the interviewer to cover the intended topics, but allowing room for the order of the proceedings to be determined by the interviewee. The topics covered included workplaces during work projects, moving between places, reasons for choosing different places and actor constellations during project phases and in different workplaces.

The interviews started with a relatively open question ('Could you please tell me something about the work organisation in your projects and the role of faceto-face-interaction in them?'), and then moved on to more specific questions. To understand the spatial settings being chosen to create temporary spatial proximity, the use of different places was focused on during the interviews. Firstly, a distinction was made between meeting venues in companies (of the service provider and the customer) and meeting venues in other locations. Secondly, other locations were differentiated with regard to places determined by the actors included in the project (mainly suppliers) and neutral places. Thirdly, neutral places were differentiated with regard to 'pragmatic places' (the primary motivation to choose these places was time or cost savings) and 'special places' (the primary motivation being the creation of a special atmosphere). During the interviews, sketches were created with a timeline for sample projects, where the locations used in the project were marked.

\section{'Move and Manage' in the work processes of knowledge-intensive services}

\section{Temporary spatial proximity in company workplaces: Workplaces as extensions of the working partners' company philosophies}

Temporary spatial proximity in company workplaces, which primarily refers to meetings in office spaces, represents the lion's share of temporary spatial proximity settings in the work processes of knowledge-intensive services. Temporary spatial proximity in the work processes of consulting services (both management and IT consulting) occurs almost exclusively in the client's office, whereas the work processes of advertising agencies occur in the offices of both the client and the service provider. For the client, the creation of temporary spatial proximity in-house is less time-consuming, and more economical, than travelling to the service provider's office or other locations. Also - most important - it enables the client to exhibit their own working philosophy and to show their own spatial, human and indirectly - financial resources.

From the service provider's perspective, meeting in the client's office at the beginning of a project enables one to experience the client's working methods and work philosophy more deeply than would be possible by merely analysing annual reports. Spatial arrangements in the client's workplaces are a source of information themselves and serve to help one to understand non-verbalised factors, such as power relations. Service providers understand the client's workplaces as extensions of their company philosophies. Therefore, visiting the partner's company workplace enables observation of the partner's 
everyday work environment, allowing additional information about the potential client or service provider to be gained. Some understanding of a client company's internal procedures and technical infrastructure is necessary. Interview partners from all three sectors emphasised the importance of 'being there' (Gertler, 1995) at the workplace.

The way in which office spaces or facilities are designed also depends, of course, on the culture and on those who occupy it. [...] To understand this, and to meet there at the client's workplace, is tremendously important because then you pick up on these issues and ask, 'Oh, does this project have any chance at all in a context like this?' (Interview 12, IT consultancy, Managing Director of an international multi-location company, Frankfurt)

Being at specific physical places enables a sensing of the atmosphere of these places, and an understanding of the work philosophies and problems of the people working in these places.

I have no need to familiarise myself with offices, but rather with machinery, logistics, material flow and all those things. Because this is how you get a bit of a feel. There are companies where you can eat off the floor, and there are other companies where you really have to watch your step because it is so grungy, owing to circumstances. But that says a great deal about a company like that. (Interview 4, management consultancy, Managing Director of a primarily national-orientated, single-location company, Bonn)

If we have a new client, we want to go there the first time because we need to see how things are there; we have to pick up the scent in some way; we need to get a feel for what kind of people work there, and in what types of rooms, what they produce, what the atmosphere is like, and so on. (Interview 5, advertising agency, Managing Director of a primarily national-orientated, single-location company, Freiburg)

The buzz related to a specific workplace consists of an information and communication ecology that has to be experienced in place, the understanding of which is useful for developing solutions in knowledge-intensive service projects.

Unlike consulting services, advertising agencies prefer to hold follow-up meetings in their own offices. These meetings serve as platforms for the first substantive discussions, as well as for the representation of the agency. Both creative and economic capabilities are presented during these meetings. The customer should - even if it happens unconsciously - experience the capabilities of the service provider by 'being there' at the service provider's workplace.

When it comes to collaboration, we are usually quite happy to have the customer come to us at times because the premises and the environment also represent us. We show the customers what our work environment looks like, how our agency looks, what infrastructure we have here, etc. (Interview 1, advertising agency, Managing Director of a primarily national-orientated, single-location company, Berlin)

They definitely want to see how we are equipped, and what kind of people are running around here. So, if an acquisition meeting has taken place at the client's office [...], the next meeting is automatically at the agency's offices. So, they certainly want to see if we are capable, also of pre-financing. (Interview 3, advertising agency, Managing Director of a primarily national-orientated, single-location company, Freiburg)

Naturally, during a project, face-to-face encounters take place at the workplace of the project participants for pragmatic reasons: meeting facilities at the participants' workplaces are easily accessible and usually less expensive than meeting elsewhere; however, the first meeting in particular plays a crucial role in experiencing the work philosophy and work processes of the work partners through 'being there'. During that first meeting, conclusions concerning sympathy and work philosophies are drawn through observations and experiences in the workplace of the other partner.

\section{Temporary spatial proximity in transit spaces: Providing convenient and private workplaces}

Temporary spatial proximity in transit spaces takes place outside the company workplaces of clients and service providers. These locations are particularly convenient to access, for example, airport conference centres, transfer hubs in the high-speed rail system or motorway service areas, outside of conurbations. Three main rationales for the use of these places were 
mentioned by the interviewees: efficiency gains; convenience; and privacy. Experiencing a specific physical place ('being there') is not the rationale behind meeting in transit spaces. On the contrary, interviewees in the advertising agency sector point to the standardised, and thus unattractive, atmosphere of transit spaces. The anonymity of the 'non-places' is sensed as strange.

If you have ever had any meetings at the airport in Frankfurt, for example, the atmosphere is simply horrible. [...] These airport clubs, they are all very practical, but hardly 'chic'. (Interview 12, advertising agency, Managing Director of an international multilocation company, Hamburg)

Despite this, these places are still frequently used for efficiency gains, to exchange information, albeit reluctantly and unenthusiastically. Transit places offer easily accessible, technically well-equipped places for face-to-face interaction, providing a degree of confidentiality that cannot be realised in third places, where competitors might observe or overhear face-to-face interactions. The confidentiality offered by transit places relates not only to competitors, but also to a company's staff, who may be talked about. Particularly in terms of combining convenience and privacy, transit spaces provide benefits that more atmospheric 'third places', such as restaurants or bars, cannot provide. Therefore, a distinctive feature of meetings in these places is either urgency or confidentiality.

Last week, for example, I was in Frankfurt and met with two clients at the airport conference centre. Because infrastructure is provided for meetings there, it's so simple. [...] [I]f a bit of privacy is required, restaurants are never a very good idea. It is better to meet in something like an airport conference room. (Interview 4, management consultancy, Managing Director of a primarily national-orientated, singlelocation company, Bonn)

Since any place outside of the involved company's workplace provides neutral ground - which might be helpful in certain situations - the distinct advantage of transit spaces is a balanced mix of efficiency and confidentiality. Developing a creative or inspiring atmosphere is not seen as a priority for meetings in transit spaces.

\section{Temporary spatial proximity at retreat places: Escaping routine through unusual workplaces}

The third type of place in which temporary spatial proximity occurs is the retreat place. An important facet of these places is the possibility of developing relationships and ideas that cannot be experienced elsewhere (Oldenburg, 1999; Slater and Jung Koo, 2010). Based on the interviews, two principal reasons were identified as rationales for the selection of retreat places. They are used in work stages where: (a) the development of new ideas is crucial (e.g. medium- and long-term strategies); and (b) the promotion of a mutually beneficial working relationship is necessary.

In the first case, retreat places should provide a new and inspiring environment, enabling attendees to leave the beaten track behind.

Tomorrow, I have a workshop with a client [...] Even though you may have made a huge effort during the previous decade $[\ldots]$, we said, well, when it comes to fundamentally new things, it is better not to do it in the workplace. [...] And now, we are going to meet in a hotel for the next two days. (Interview 22, management consultancy, Managing Director of an international multi-location company, Hamburg)

Especially when it comes to the analysis of annual trends, then you have to retreat. [...] Of course, you have to get people out of their routines like that sometimes. (Interview 3, advertising agency, Managing Director of a primarily national-orientated, singlelocation company, Freiburg)

Escaping routine through unusual workplaces, in order to develop new strategies, was described by the interviewees in all three sectors. In this context, a specific place was chosen in order to benefit from a particular environment and its buzz. This links temporary spatial proximity at retreat places with temporary spatial proximity at workplaces. In both cases, the place is expected to influence interaction; however, at workplaces, the physical setting itself provides information that influences and enriches interaction, whereas at retreat places the physical setting is expected to stimulate interaction and creativity or - mainly mentioned by consultancy services interviewees - to promote a 
mutually beneficial working relationship. This can be explained by the intensive collaboration of service providers and clients for a longer period in one place, usually the client's workplace. After working together for some time in a specific location, a change of location provides new impetus.

In the second case, a shared identification of all project participants with the project's objectives, and the approach necessary to achieve those objectives (Rallet and Torre, 2009), is supported by team-bonding in retreat places. The shared identification is supported by tearing the stakeholders away from their routines, and allowing the stakeholders to get acquainted beyond the work itself. Short, intensive meetings with the members of the project group in a pleasant environment strengthen their identification with the project team and its objectives, thus promoting the motivation to work.

Then we'll take the whole group to a hotel in [city], a beautiful setting with a nice ambience, for two days. [...] Mobiles are not allowed in the meetings. E-mails can only be checked during breaks. People must be fully present. (Interview 31, management consultancy, Managing Director of an international multi-location company, Düsseldorf)

The same approach is implemented when a crisis arises in an ongoing project.

And when there is a crisis, the first thing you have to do is get your ducks in a row again and put everything in order, in which case you're better off going anywhere in the middle of nowhere, closing down for a day, and having a nice collective meeting. (Interview 19, management consultancy, Managing Director of an international multi-location company, Hamburg)

In this context, the disengagement from daily routine plays a major role, meeting the description of 'third places' as not just places to escape to, but also being enabling places that provide a temporary world (Glover and Parry, 2009; Oldenburg, 1999; Slater and Jung Koo, 2010). In the everyday workplace, with the usual flow of communication (incoming emails, incoming phone calls, talking in the corridor), it can be difficult to think outside the box, or to leave conflicting routines behind. Both in terms of new ideas and paradigms, and identification with a new team, the aim of using different physical spaces as retreat places is to create a pleasant and, above all new, dynamic and creative atmosphere. The change of location makes it more difficult to persist in known patterns than would be the case in the familiar office rut.

\section{Settings of 'Move and Manage' as relative places in the work process}

The findings from the interviews with stakeholders from the management and IT consultancies and the advertising agency show that, for creating temporary spatial proximity of the 'Move and Manage' type, various places are important.

\section{Synopsis}

The analysis indicates that temporary spatial proximity of the 'Move and Manage' type is organised purposefully in work processes. A purposeful use of different 'physical places of meetings' was observed (see also Bathelt and Henn, 2014: 1412).

Naturally, actors try to meet in time- and cost-saving spatial settings, and the duration, as well as the spontaneity, of the meeting also influence the chosen location. Short-term (up to several hours) and spontaneous meetings take place rather at the stakeholder's site and in transit places, whereas long-term meetings (from one day to several days) and meetings that are planned in the long term can take place in retreat places. This can be explained easily by the availability of these sites; however, the duration, per se, is not a sufficient explanation for the choice of location. The duration and also the spontaneity of the meeting depend on the agenda, and on the benefits expected from different environments (see Figure 2).

Although all three types of physical places, based on the differentiation by Rallet and Torre (2009), have been used as settings of physical places, the benefits provided by each type differ. The main differences involve the role of physical places in relation to interaction processes. The physical environments of workplaces and retreat places serve as sources of information themselves and are used to influence interaction processes by supporting creativity (retreat places) or 


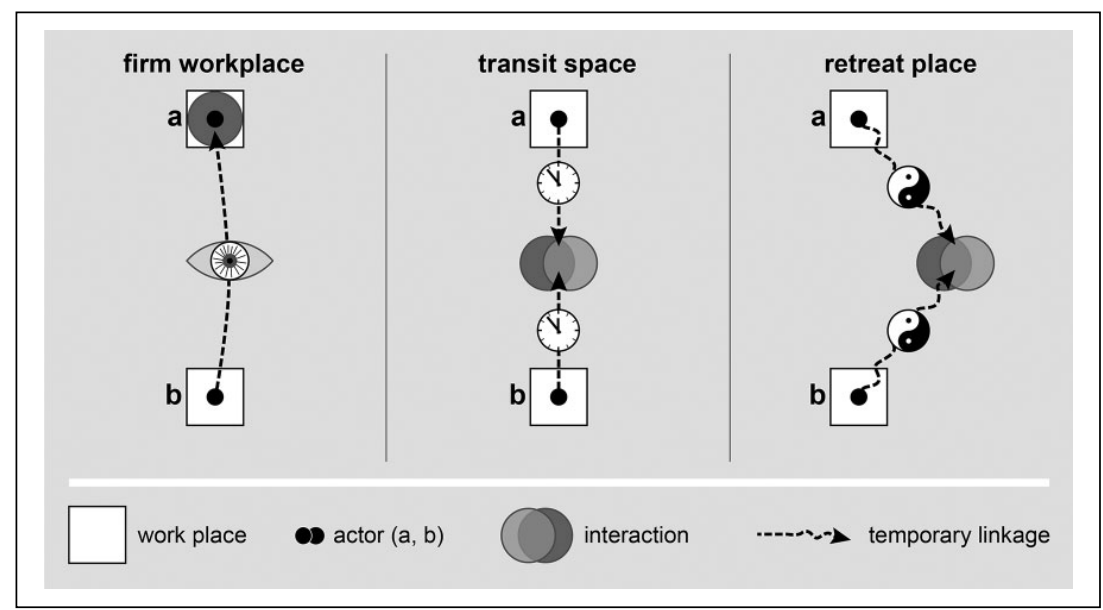

Figure 2. Three types of 'Move and Manage'

Source: Own research.

Table 2. Main logics of the three types of 'Move and Manage'.

\begin{tabular}{|c|c|c|c|}
\hline & Firm workplaces & Transit spaces & Retreat spaces \\
\hline $\begin{array}{l}\text { Informational } \\
\text { logic }\end{array}$ & $\begin{array}{l}\text { Main logic influencing } \\
\text { interaction at firm workplaces } \\
\text { from the service provider's } \\
\text { perspective: information can } \\
\text { be gained through observation } \\
\text { and experiencing the } \\
\text { workplace-related buzz }\end{array}$ & $\begin{array}{l}\text { Main logic influencing interaction } \\
\text { at transit spaces from the from } \\
\text { the service provider's and } \\
\text { client's perspectives: efficiency } \\
\text { and privacy with regard to } \\
\text { information exchange are priority }\end{array}$ & \\
\hline Creative logic & & & $\begin{array}{l}\text { Main logic influencing } \\
\text { interaction at retreat spaces } \\
\text { from the client's perspective: } \\
\text { enabling new ideas and } \\
\text { perspectives 'out of the box' }\end{array}$ \\
\hline Power logic & $\begin{array}{l}\text { Main logic influencing } \\
\text { interaction at firm workplaces } \\
\text { from the client's perspective: } \\
\text { displaying resources and the } \\
\text { firm's reputation }\end{array}$ & & $\begin{array}{l}\text { Main logic influencing } \\
\text { interaction at retreat spaces } \\
\text { from the service provider's } \\
\text { perspective: softening hardened } \\
\text { structures or conflicts }\end{array}$ \\
\hline
\end{tabular}

Source: Own research.

displaying resources (workplaces). The physical environment of transit spaces is not seen as a source or supporting influence. However, the role of physical places can differ according to the service provider's or the client's perspective (see Table 2).

The company workplace is seen as an extension and materialisation of a company's philosophy, and therefore is chosen by the service providers to better observe and understand the clients. In this context, observing a specific place enables conclusions to be drawn about the atmosphere at the client's work place, and their financial resources and work processes, overall contributing to a workplace-related buzz. Understanding this specific buzz, joint to a 
particular workplace, is an important foundation to enabling trust between the partners, and also as a starting point for the development of strategies and ideas specific to the client (Growe 2018).

Transit spaces are mainly used to save time, as they are usually linked to transport infrastructure; however, the easy accessibility of these spaces has led to the provision of meeting facilities, enabling a protected and convenient work environment outside the company. The observation or creation of a specific atmosphere is not the reason for choosing these places.

Retreat places are - like transit spaces - used for interaction outside the company; however, cost- and time-saving reasons are not prioritised. Escaping routine and creating a special atmosphere, either to create new ideas or strategies, or to resolve conflicts, is the main reason for choosing retreat places. Interestingly, the extensive use of retreat places for cultivating relationships (e.g. the service provider invites the client to an expensive hotel) has declined in recent decades due to increasingly stringent corporate compliance policies. Despite this, the need to change physical places to create a different and inspiring atmosphere still exists. Therefore, in recent times, the use of retreat places has been mainly to support the creation of new, out-of-thebox ideas, to support the creation of a dynamic 'buzz'-like atmosphere. Interesting business ideas have developed to fulfil this need. One example is Spacebase, a Berlin-based company catering to the need for a broad variety of places for face-to-face encounters in urban agglomerations through procuring meeting rooms - like AirBnB does with lodging facilities - in companies, studios or private flats, for business purposes, to provide different (creative) atmospheres for face-to-face encounters (Brankovic, 2017). Spacebase advertises its services on the company webpage as offering 'exciting and unique locations that will [...] boost your creativity'. This offer is especially interesting for companies that cannot provide a variety of physical places. Services like Spacebase support this study's argument that physical places are interrelated with interaction processes.

Actors from all three sectors - advertising, management and IT - emphasised the importance of meetings at company workplaces, either to facilitate the understanding of clients through observing the client's workplace, or to demonstrate their own capabilities by displaying their in-house environment. The importance of meetings in transit places was also acknowledged by actors from all sectors. There are, however, differences in the use of retreat places. In particular, the use of retreat places to create a supportive work atmosphere was mentioned much more by actors in management and IT than by actors in the advertisement sector. The temporary joint daily work routine during consultancy projects leads to a higher danger of cabin fever in the project, and increases the need to escape, temporarily, to a new setting. In this regard, the results of this study may not only be limited to knowledge-intensive services, but may also be applied to other sectors that are primarily based on the exchange and generation of knowledge, as well as on intensive interaction with clients, or through collaboration with partners during work processes (e.g. research-intensive situations). Restrictions on their application to other sectors can be seen where knowledge creation is neither based on interaction nor on participation.

\section{Further implications}

Beyond the specific types of places analysed in this study, the findings shed light on the interrelation of the concept of 'buzz' and physical places of temporary spatial proximity (Robertsson and Marjavaara, 2014). As the concept of buzz is discussed as an important concept in the knowledge economy, particularly in the creative and cultural industries (Currid and Williams, 2010; Mould and Joel, 2010; Storper and Venables, 2004), one important question is how companies contribute to, or benefit from, the 'buzz' (Mould and Joel, 2010). Although different scales (local and global, city and region) are linked to the concept of buzz, the conceptualisation of buzz, so far, mainly focuses on social interaction (Moodysson, 2008), on practices (Gertler, 2008), on networks (Mould and Joel, 2010) and on milieus (Currid and Williams, 2010).

In understanding the exchange of specific information, and intended and unanticipated learning processes in organised and accidental meetings (Bathelt et al., 2004: 38), as buzz, the findings of this study indicate that buzz can occur on very small scales (e.g. workplaces and retreat places) during temporary spatial proximity, in which actors from different companies interact and learn. Different physical 
places are chosen purposefully to either observe buzz so as to understand the actors (choice of workplaces) or to create a specific dynamic and innovative buzz (choice of retreat places).

This kind of 'micro-buzz' (smaller in scale than the local buzz that often refers to cities) derives its importance from the temporality of projects. In different project phases, different kinds of interaction follow each other (getting acquainted, developing a strategy, etc.). Different kinds of interaction can be supported by different physical locations, with their specific fluid atmospheres.

The findings indicate that there is a need for further research in two particular directions; firstly, on the role played by changing different physical places during work processes. This study has shown that changing physical environments during work processes plays a role in the knowledge economy through gaining different advantages from diverse physical places. By means of site-specific studies, the role of diverse place concepts, for example, 'third places', or 'non-places', in the work processes of knowledge-intensive services could be further elucidated. The advantages of different places, and the use of different places during projects, can shed light on necessary interaction modes. Secondly, the so far under-researched aspect of the physical embeddedness of buzz could be expanded. Although the scale of buzz is a topic of academic papers (e.g. global or local buzz) and the grounding of the buzz in places is subject to definitions of the buzz, the actual physical places and their interrelation with interaction processes, through the creation of a 'microbuzz', are still a black box in many cases.

\section{Acknowledgements}

The author thanks two anonymous reviewers for their constructive comments on an earlier version of this paper. The usual disclaimers apply.

\section{Declaration of Conflicting Interests}

The author(s) declared no potential conflicts of interest with respect to the research, authorship, and/or publication of this article.

\section{Funding}

The author(s) disclosed receipt of the following financial support for the research, authorship, and/or publication of this article: The author thanks the Fritz Thyssen Stiftung
Foundation [Grant Number Az. 20.13.0.042] for financial support which enabled this research.

\section{References}

Aguiléra A, Lethiais V and Rallet A (2014) Spatial proximity and intercompany communication: myths and realities. European Planning Studies 23(4): 798-810.

Allen TJ and Henn GW (2007) The Organization and Architecture of Innovation: Managing the Flow of Technology. Amsterdam: Butterworth-Heinemann.

Anand N and Watson MR (2004) Tournament rituals in the evolution of fields: the case of the Grammy Awards. Academy of Management Journal 47(1): 59-80.

Asheim B, Coenen L and Vang J (2007) Face-to-face, buzz, and knowledge bases: sociospatial implications for learning, innovation, and innovation policy. Environment and Planning C: Government and Policy 25(5): 655-670.

Augé M (2008) Non-Places: An Introduction to Supermodernity. London: Verso.

Bathelt H and Henn S (2014) The geographies of knowledge creation over distance: toward a typology. Environment and Planning A 46(6): 1403-1424.

Bathelt H and Gibson R (2015) Learning in 'Organized Anarchies': the nature of technological search processes at trade fairs. Regional Studies 49(6): 985-1002.

Bathelt H and Schuldt N (2008) Between luminaires and meat grinders: international trade fairs as temporary clusters. Regional Studies 42(6): 853-868.

Bathelt $\mathrm{H}$ and Schuldt N (2010) International trade fairs and global buzz, part I: ecology of global buzz. European Planning Studies 18(12): 1957-1974.

Bathelt $\mathrm{H}$ and Turi P (2011) Local, global and virtual buzz: the importance of face-to-face contact in economic interaction and possibilities to go beyond. Geoforum 42(5): 520-529.

Bathelt H, Malmberg A and Maskell P (2004) Clusters and knowledge: local buzz, global pipelines and the process of knowledge creation. Progress in Human Geography 82(1): 31-56.

Beaverstock JV and Budd L (2013) International business travel in a digital world economy. Research in Transportation Business \& Management 9: 1-4.

Bettencourt LA, Ostrom AL, Brown SW and Roundtree RI (2002) Client co-production in knowledge-intensive business services. California Management Review 44(4): 100-128.

Borges S, Ehmann S and Klanten R (2013) Workscape: New Spaces for New Work. Berlin: Gestalten.

Brankovic M (2017) Start-up-Atmosphäre kann man mieten. Frankfurter Allgemeine Zeitung - Beruf \& Chance, 10 January. http://www.faz.net/aktuell/ 
beruf-chance/die-gruender/gruenderserie-start-upatmosphaere-kann-man-mieten-14610339.html

Brown T and Kātz B (2009) Change by Design: How Design Thinking Transforms Organizations and Inspires Innovation. New York: Harper Business.

Cook IR and Ward K (2012) Conferences, informational infrastructures and mobile policies: the process of getting Sweden 'BID ready'. European Urban and Regional Studies 19(2): 137-152.

Costas J (2013) Problematizing mobility: a metaphor of stickiness, non-places and the kinetic elite. Organization Studies 34(10): 1467-1485.

Currid E and Williams S (2010) The geography of buzz: art, culture and the social milieu in Los Angeles and New York. Journal of Economic Geography 10(3): 423-451.

Entwistle J and Rocamora A (2006) The field of fashion materialized: a study of London Fashion Week. Sociology 40(4): 735-751.

Faulconbridge J, Beaverstock JV, Derudder B and Witlox F (2009) Corporate ecologies of business travel in professional service firms: working towards a research agenda. European Urban and Regional Studies 16(3): 295-308.

Flögel F and Zademach H-M (2017) Bank branches as places of knowledge creation: conceptual considerations and empirical findings at the micro-geographical scale. Erdkunde 71(4): 301-312.

Gallie E-P and Guichard R (2005) Do collaboratories mean the end of face-to-face interactions? An evidence from the ISEE project. Economics of Innovation and New Technology 14(6): 517-532.

Georgi W (2016) The Other Office: Creative Workplace Design. Amsterdam: Frame Publishers.

Gertler MS (1995) "Being there": proximity, organization, and culture in the development and adoption of advanced manufacturing technologies. Economic Geography 71(1): 1-26.

Gertler MS (2003) Tacit knowledge and the economic geography of context, or the undefinable tacitness of being (there). Journal of Economic Geography 3(1): 75-99.

Gertler MS (2008) Buzz without being there? Communities of practice in context. In: Amin A and Roberts J (eds) Community, Economic Creativity, and Organization. Oxford: Oxford University Press, pp. 203-226.

Glover TD and Parry DC (2009) A third place in the everyday lives of people living with cancer: functions of Gilda's Club of Greater Toronto. Health \& Place 15(1): 97-106.

Grabher G (2002a) Cool projects, boring institutions: temporary collaboration in social context. Regional Studies 36(3): 205-214.
Grabher G (2002b) The project ecology of advertising: tasks, talents and teams. Regional Studies 36(3): 245-262.

Grabher G (2004) Learning in projects, remembering in networks? Communality, sociality, and connectivity in project ecologies. European Urban and Regional Studies 11(2): 103-123.

Grabher G and Thiel J (2015) Projects, people, professions: trajectories of learning through a mega-event (the London 2012 case). Geoforum 65: 328-337.

Grabher G, Melchior A, Schiemer B, Schüßler E and Sydow J (2017) From being there to being aware: confronting geographical and sociological imaginations of copresence. Environment and Planning $A$ 50(1): 245-255.

Growe A (2018) Developing trust in face-to-face interaction of knowledge-intensive business services (KIBS). Regional Studies 9(1), 1-11. Online First. https://doi.org/10.1080/00343404.2018.1473567

Gustafson P (2013) Business travel from the traveller's perspective: stress, stimulation and normalization. Mobilities 9(1): 1-21.

Henn S and Bathelt H (2015) Knowledge generation and field reproduction in temporary clusters and the role of business conferences. Geoforum 58: 104-113.

Ibert O (2004) Projects and firms as discordant complements: organisational learning in the Munich software ecology. Research Policy 33(10): 1529-1546.

Jansson J (2014) Temporary events and spaces in the Swedish primary art market. Zeitschrift für Wirtschaftsgeographie 58(4): 202-215.

Jon Hawkins C and Ryan L-AJ (2013) Festival spaces as third places. Journal of Place Management and Development 6(3): 192-202.

Kohlert C and Cooper SM (2017) Space for Creative Thinking: Design Principles for Work and Learning Environments. Munich: Callwey.

Lampel J and Meyer AD (2008) Guest editors' introduction: field-configuring events as structuring mechanisms: how conferences, ceremonies, and trade shows constitute new technologies, industries, and markets. Journal of Management Studies 45(6): 1025-1035.

Lange B, Power D and Suwala L (2014) Geographies of field-configuring events. Zeitschrift für Wirtschaftsgeographie 58(4): 187-201.

Levy D and Scully M (2007) The institutional entrepreneur as modern prince: the strategic face of power in contested fields. Organization Studies 28(7): 971-991.

Li P-F (2014) Global temporary networks of clusters: structures and dynamics of trade fairs in Asian economies. Journal of Economic Geography 14(5): 995-1021. 
McNeill D (2009) The airport hotel as business space. Geografiska Annaler, Series B: Human Geography 91(3): 219-228.

Maskell P, Bathelt H and Malmberg A (2006) Building global knowledge pipelines: the role of temporary clusters. European Planning Studies 14(8): 997-1013.

Miller R (2014) Change Your Space, Change Your Culture: How Engaging Workspaces Lead to Transformation and Growth. Hoboken, NJ: Wiley.

Moodysson J (2008) Principles and practices of knowledge creation: on the organization of "Buzz" and "Pipelines" in life science communities. Economic Geography 84(4): 449-469.

Mould O and Joel S (2010) Knowledge networks of "buzz" in London's advertising industry: a social network analysis approach. Area 42(3): 281-292.

Müller M and Stewart A (2015) Does temporary geographical proximity predict learning? Knowledge dynamics in the Olympic Games. Regional Studies. 50(3): 1-14.

Nilsson M and Mattes J (2015) The spatiality of trust: factors influencing the creation of trust and the role of face-to-face contacts. European Management Journal 33(4): 230-244.

Norcliffe G and Rendace O (2003) New geographies of comic book production in North America: the new artisan, distancing, and the periodic social economy. Economic Geography 79(3): 241-263.

Oldenburg R (1999) The Great Good Place: Cafés, Coffee Shops, Bookstores, Bars, Hair Salons, and Other Hangouts at the Heart of a Community. New York; Cambridge, MA; Berkeley, CA: Marlowe.

Porter ME (2003) Locations, clusters, and company strategy. In: Clark GL, Feldman MP and Gertler MS (eds) The Oxford Handbook of Economic Geography. Oxford: Oxford University Press, pp. 253-274.

Power D and Jansson J (2008) Cyclical clusters in global circuits: overlapping spaces in furniture trade fairs. Economic Geography 84(4): 423-448.

Pütz O (2012) From non-places to non-events: the airport security checkpoint. Journal of Contemporary Ethnography 41(2): 154-188.

Rallet A and Torre A (2009) Temporary Geographical Proximity for Business and Work Coordination: When, How and Where? (SPACES online No. 02). Retrieved from http://citeseerx.ist.psu.edu/viewdoc/download?doi $=10.1 .1 .169 .8174 \&$ rep $=$ rep1\&type $=$ pdf

Ramírez-Pasillas M (2008) Resituating proximity and knowledge cross-fertilization in clusters by means of international trade fairs. European Planning Studies 16(5): 643-663.
Rinallo D and Golfetto F (2006) Representing markets: the shaping of fashion trends by French and Italian fabric companies. Industrial Marketing Management 35(7): 856-869.

Robertsson L and Marjavaara R (2014) The seasonal buzz: knowledge transfer in a temporary setting. Tourism Planning \& Development 12(3): 251-265.

Rutten R (2014) Learning in socio-spatial context: an individual perspective. Prometheus 32(1): 67-74.

Rutten R (2017) Beyond proximities: the socio-spatial dynamics of knowledge creation. Progress in Human Geography 41(2): 159-177.

Rutten R and Boekema F (2012) From learning region to learning in a socio-spatial context. Regional Studies 46(8): 981-992.

Rychen F and Zimmermann J-B (2008) Clusters in the global knowledge-based economy: knowledge gatekeepers and temporary proximity. Regional Studies 42(6): 767-776

Schüßler E, Grabher G and Müller-Seitz G (2015) Fieldconfiguring events: arenas for innovation and learning? Industry \& Innovation 22(3): 165-172.

Schuldt N and Bathelt H (2011) International trade fairs and global buzz. Part II: practices of global buzz. European Planning Studies 19(1): 1-22.

Slater A and Jung Koo H (2010) A new type of "Third Place"? Journal of Place Management and Development 3(2): 99-112.

Storper M and Venables AJ (2004) Buzz: face-to-face contact in the urban economy. Journal of Economic Geography 4(4): 351-370.

Strambach S (2008) Knowledge-Intensive Business Services (KIBS) as drivers of multilevel knowledge dynamics. International Journal of Service and Technology Management 10(2-4): 152-174.

Strengers Y (2015) Meeting in the global workplace: air travel, telepresence and the body. Mobilities 10(4): 592-608.

Torre A (2008) On the role played by temporary geographical proximity in knowledge transmission. Regional Studies 42(6): 869-889.

Torre A (2011) The role of proximity during long-distance collaborative projects. Temporary geographical proximity helps. International Journal of Foresight and Innovation Policy 7(1-3): 213-230.

Torre A (2015) Permanent and temporary proximities: their role in the process of technological knowledge diffusion. Revista Brasileira de Gestao e Desenvolvimento Regional 11(4): 78-100.

Urry J (2007) Mobilities. Cambridge: Polity Press.

Wood P (2002) Knowledge-intensive services and urban innovativeness. Urban Studies 39(5-6): 993-1002. 